\title{
Nitrilase Homolog 1
}

National Cancer Institute

\section{Source}

National Cancer Institute. Nitrilase Homolog 1. NCI Thesaurus. Code C126585.

Nitrilase homolog 1 (327 aa, $38 \mathrm{kDa}$ ) is encoded by the human NIT 1 gene. This protein plays a role in both nitrogen compound metabolism and the positive regulation of apoptosis. 